\title{
ORNL Slicer 2 v0.93 BETA
}

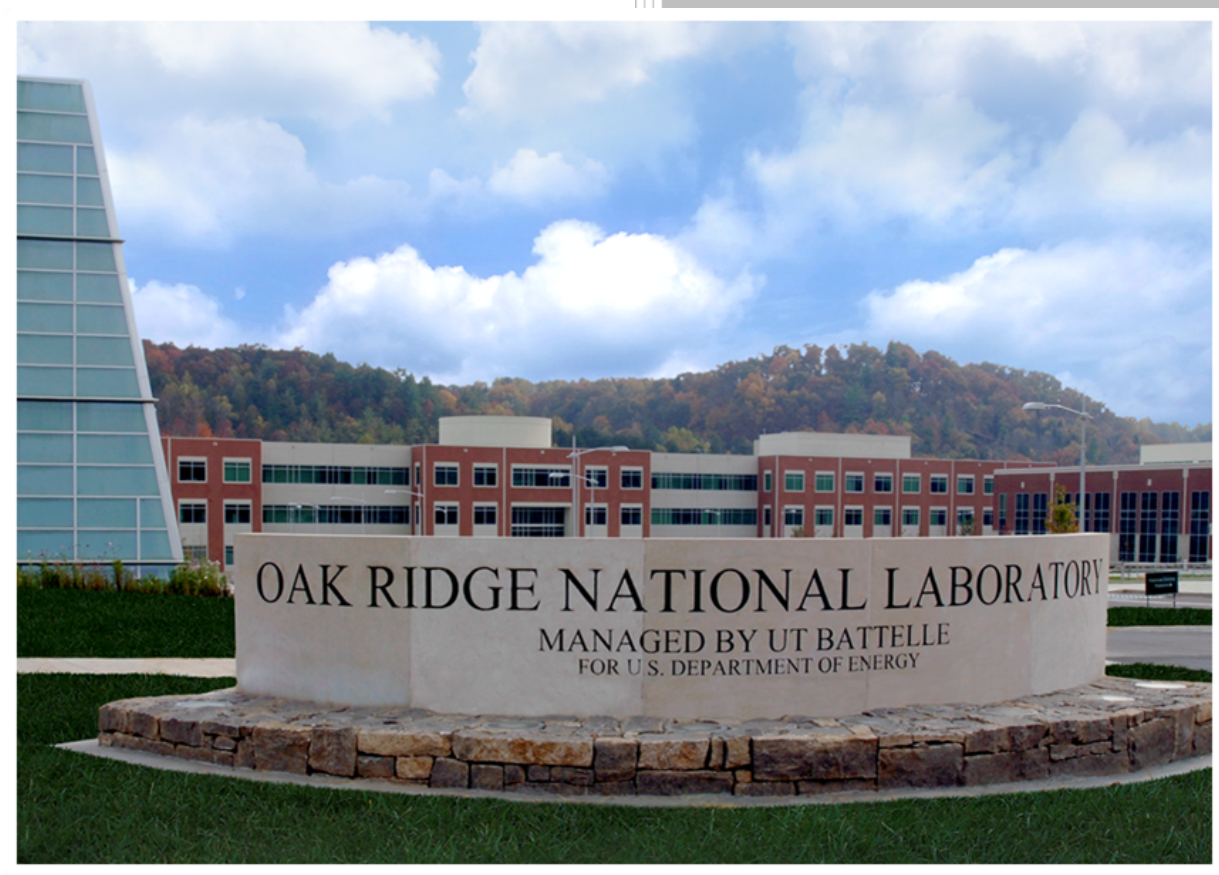

Alex Roschli

Michael Borish

Canhai Lai

$3 / 31 / 2021$

Approved for public release.

Distribution is unlimited. 


\title{
DOCUMENT AVAILABILITY
}

Reports produced after January 1, 1996, are generally available free via US Department of Energy (DOE) SciTech Connect.

Website www.osti.gov

Reports produced before January 1, 1996, may be purchased by members of the public from the following source:

\author{
National Technical Information Service \\ 5285 Port Royal Road \\ Springfield, VA 22161 \\ Telephone 703-605-6000 (1-800-553-6847) \\ TDD 703-487-4639 \\ Fax 703-605-6900 \\ E-mail info@ntis.gov \\ Website http://classic.ntis.gov/
}

Reports are available to DOE employees, DOE contractors, Energy Technology Data Exchange representatives, and International Nuclear Information System representatives from the following source:

Office of Scientific and Technical Information

PO Box 62

Oak Ridge, TN 37831

Telephone 865-576-8401

Fax 865-576-5728

E-mail reports@osti.gov

Website http://www.osti.gov/contact.html

This report was prepared as an account of work sponsored by an agency of the United States Government. Neither the United States Government nor any agency thereof, nor any of their employees, makes any warranty, express or implied, or assumes any legal liability or responsibility for the accuracy, completeness, or usefulness of any information, apparatus, product, or process disclosed, or represents that its use would not infringe privately owned rights. Reference herein to any specific commercial product, process, or service by trade name, trademark, manufacturer, or otherwise, does not necessarily constitute or imply its endorsement, recommendation, or favoring by the United States Government or any agency thereof. The views and opinions of authors expressed herein do not necessarily state or reflect those of the United States Government or any agency thereof. 
Manufacturing Science Division

\title{
ORNL Slicer 2 v0.93 BETA Technical Memo
}

\author{
Alex Roschli \\ Michael Borish \\ Canhai Lai
}

Date Published:

$3 / 31 / 2021$

Prepared by

OAK RIDGE NATIONAL LABORATORY

Oak Ridge, TN 37831-6283

managed by

UT-BATTELLE, LLC

for the

US DEPARTMENT OF ENERGY

under contract DE-AC05-00OR22725 



\section{CONTENTS}

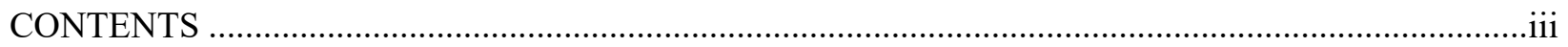

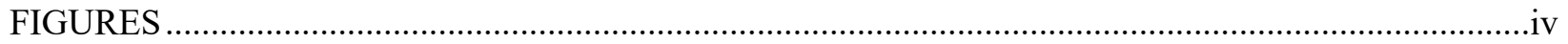

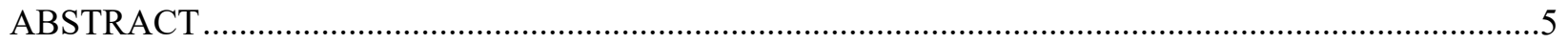

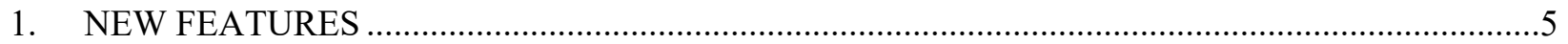

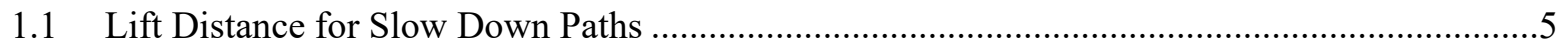

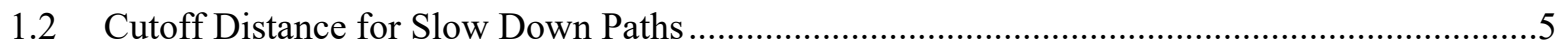

1.3 Pre and Post Pause G-Code Settings for Add Dwell Time ...................................................6

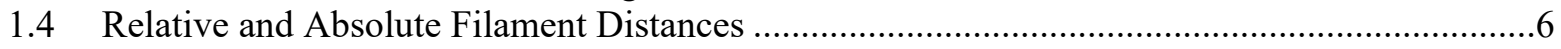

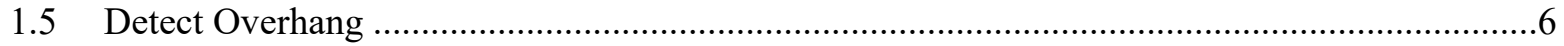

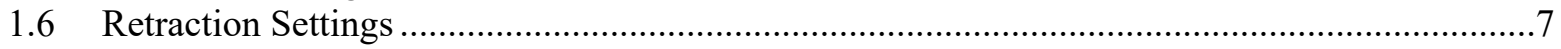

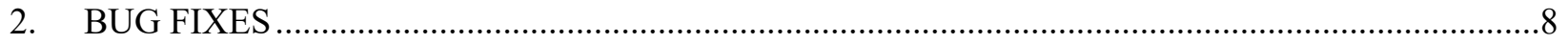

2.1 Inappropriately Spaced Gridlines for Non-Rectangular Volumes .........................................8

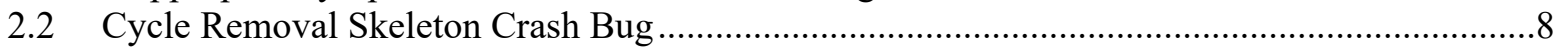

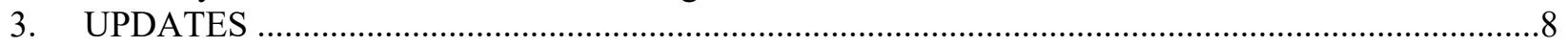

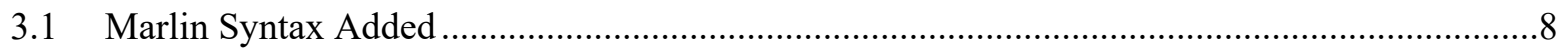

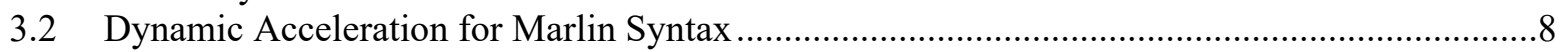

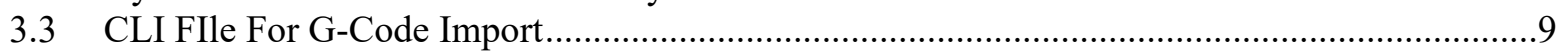

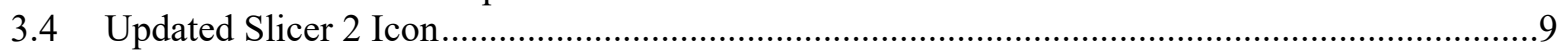

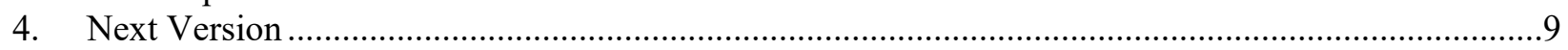




\section{FIGURES}

Figure 1: Hexagonal toolpath with lifting slow down shown in green and cutoff distance in pink

Figure 2: STL with overhanging faces colored red. The detect overhang button can be seen, circled in red, at the top right. .....

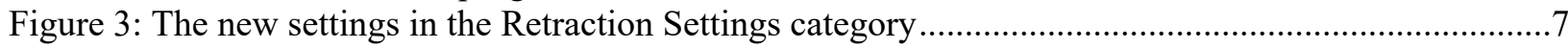

Figure 4: Cylindrical build volume with properly generated grid lines..................................................

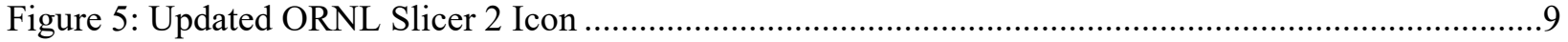




\begin{abstract}
ORNL Slicer $2 \mathrm{v} 0.93$ BETA is the fourth BETA release of the ORNL Slicer 2 software package. It was released on 3/31/2021 to all users of v0.92, currently totaling over 100 users. This technical memo will highlight all of the new features, updates, and bug fixes released in this latest iteration of the ORNL Slicer 2 .
\end{abstract}

\title{
1. NEW FEATURES
}

\subsection{LIFT DISTANCE FOR SLOW DOWN PATHS}

Slow down is a path modifier applied to the end of the toolpath. It is used to allow the user to take control of the end of the path, by adjusting the extruder and gantry speeds for a set distance of the path length. It is helpful for slowing down an extruder to compensate for the spindle releasing pressure created within the barrel. This pressure release, if not accounted for, can cause a buildup of material at the end of the path.

Most systems have a nozzle facing straight down. The material flows down onto the substrate and the nozzle moves forward creating a bead that follows the extruder. Other systems, such as ORNL SkyBAAM, have a nozzle that leads the material flow and extrudes material out the back of the nozzle. This makes closed loop paths a challenge because the leading part of the nozzle will collide with the printed material when closing the loop. The solution is to lift the extruder at the end of the path, during the slow down modifier. To do this a new setting was added for each slow down type so that the lift can be defined. The lift is done uniformly during the entire length of the slow down move. Figure 1 shows a lifting slow down motion.

\subsection{CUTOFF DISTANCE FOR SLOW DOWN PATHS}

During the slow down path modifier motion, the user defines the extruder speed. This is often set as a lower speed than the printing extruder speed to help slow down and release pressure in the extruder. It can also be set to zero to turn the extruder off and allow material to ooze out of the extruder while completing the path. For the ORNL SkyBAAM system, a slow down distance is used to initiate the lifting motion prior to the end of the path while giving enough distance to lift without collision. The distance to start the lift motion is farther from the end of the path than the distance where the extruder needs cut off. This creates a need for a new setting, a cutoff distance setting, that defines a distance from the end of the path to turn off the extruder. This functionality works independently of the slow down distance so that both a slow down and a cutoff can be used. Figure 1 shows a lifting slow down with a cutoff distance applied to the end.

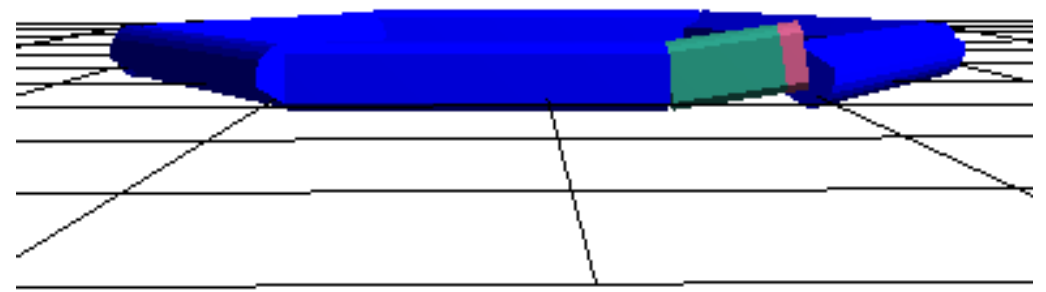

Figure 1: Hexagonal toolpath with lifting slow down shown in green and cutoff distance in pink 


\subsection{PRE AND POST PAUSE G-CODE SETTINGS FOR ADD DWELL TIME}

Most materials, regardless of thermoplastic, concrete, or metal, require a minimum layer time during printing such that layers must meet or exceed the minimum time. When layers are printed too fast, heat buildup can cause the print to collapse and fail. To compensate for this, ORNL Slicer can slow the toolpaths using a feedrate modification or issue a pause command at the end of the layer. When pausing, the user needs the ability to control what activity happens before/during/after the pause. This is now configurable with pre and post pause custom G-Code settings within the Materials Settings.

\subsection{RELATIVE AND ABSOLUTE FILAMENT DISTANCES}

Filament extrusion systems operate in one of two modes: relative and absolute. Relative mode, initiated with the G91 command, issues a filament extrusion command on each line that is with respect to zero. So a line that is "G1 E10" would extrude the filament $10 \mathrm{~mm}$. The other option, absolute, extrudes filament with respect to the current position of the E axis. If the E axis is at 0, then the line "G1 E10" would extruder $10 \mathrm{~mm}$ of filament. If the next line is "G1 E12" then just $2 \mathrm{~mm}$ of filament would be extruded. Absolute mode is initiated with the G90 command. Relative vs absolute is defined with a checkbox in the filament settings.

\subsection{DETECT OVERHANG}

Overhangs are triangular STL faces that exceed a user defined angle in the support settings. This angle, measured from the vertical, is often 45 degrees. Faces that overhang by more than 45 degrees can be difficult to print because not enough of the bead is supported by the previous layer, and thus falls or sags. To determine if the part needs support, a detect overhangs button has been added to the Part View Tab. When enabled, faces exceeding the threshold angle are colored red so that the user can easily see where supports will be needed. Figure 2 shows an STL with red overhanging triangles colored as well as the button to enable/disable detect overhangs. 


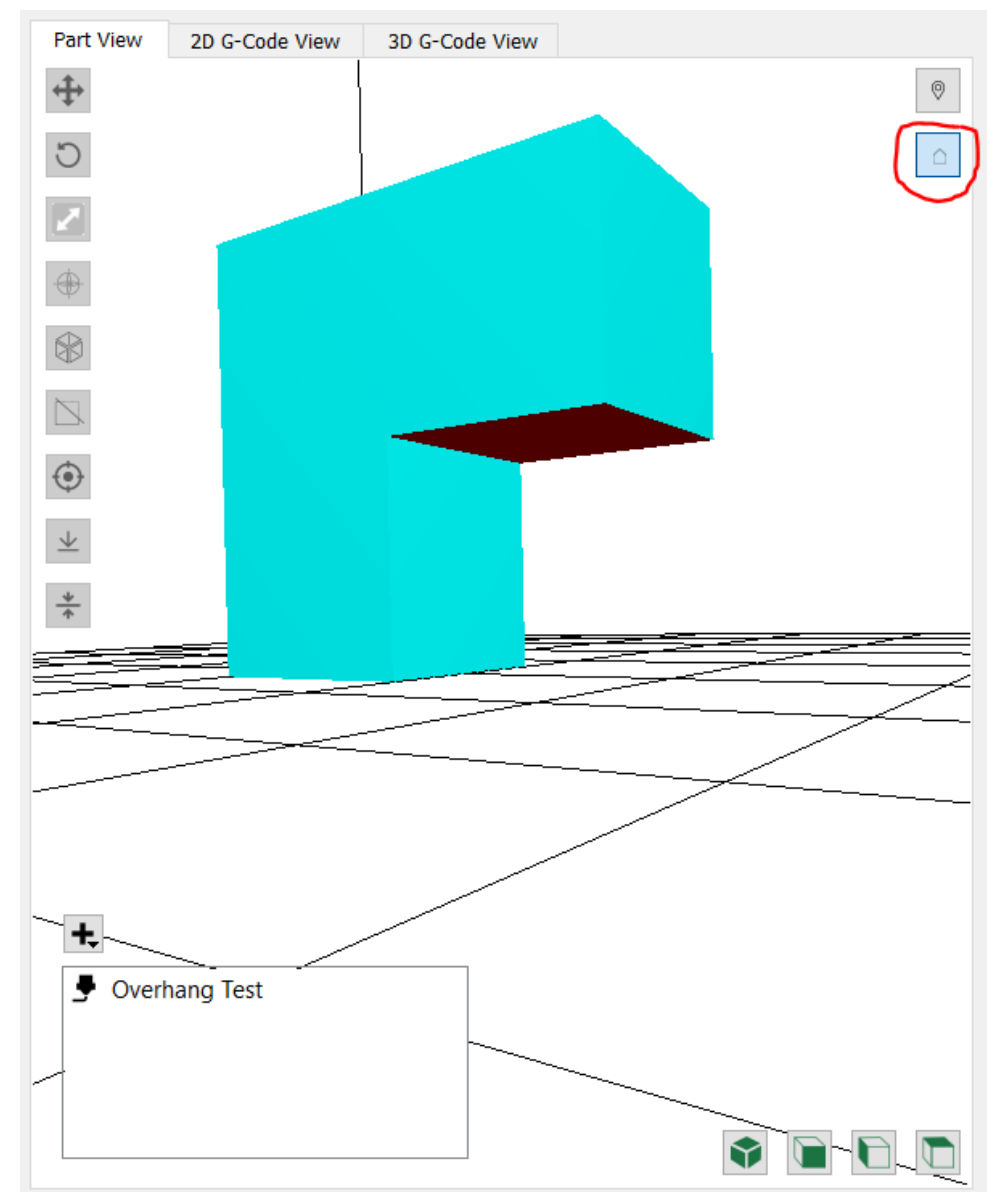

Figure 2: STL with overhanging faces colored red. The detect overhang button can be seen, circled in red, at the top right.

\subsection{RETRACTION SETTINGS}

ORNL Slicer $2 \mathrm{v} 0.93$ is the first version to truly support filament printing via the Marlin syntax. An important component of filament printing is retraction. Retraction is used before lifting or traveling so that filament doesn't ooze out of the nozzle. To control this, several settings are needed such as retraction distance and speed. At the start of the path, after retracting, a priming motion is needed to prepare the extruder continue printing. Figure 3 shows all the new settings added for configuring retraction.

Enable Retraction
Minimum Travel for Retraction
Retraction Length
Retraction Speed
Retract on Layer Change
Prime Speed
Additional Prime Length
Figure 3. The new settings in the Retraction Settings category




\section{BUG FIXES}

\subsection{INAPPROPRIATELY SPACED GRIDLINES FOR NON-RECTANGULAR VOLUMES}

Grid lines are generated across the floor of the build volume to help with alignment and to give the user perspective of the area. For rectangular volumes, grid lines are just lines in the $\mathrm{X}$ and $\mathrm{Y}$ directions that are spaced according to the user defined value. For cylindrical and toroidal volumes, the lines must be clipped in a circular shape, so the lines can be of many different lengths. A bug existed where lines weren't generating and clipping correctly. This has since been corrected, and the result can be seen in Figure 4.

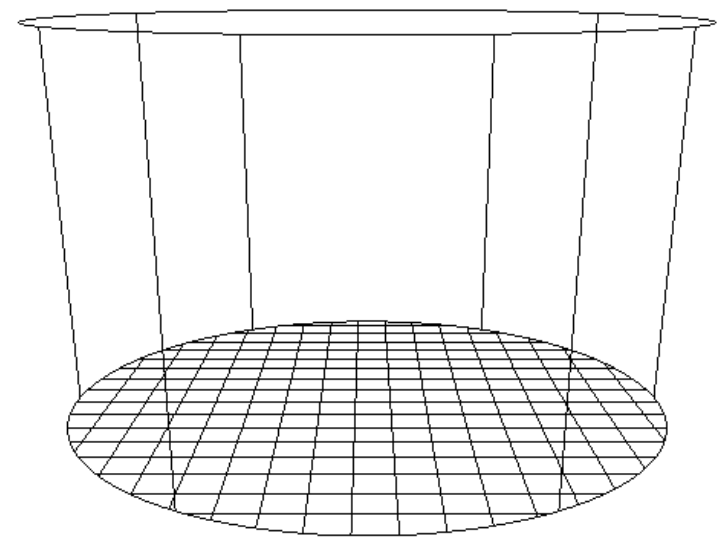

Figure 4: Cylindrical build volume with properly generated grid lines

\subsection{CYCLE REMOVAL SKELETON CRASH BUG}

Fixed a bug during skeleton creation that would cause a crash. To appropriately generate skeletons, one of the steps involves cycle removal. In general, skeleton pathing must remove cycles to prevent crossing on top of previously deposited paths. This bug concerned an edge case where removal of the cycle involved removal of an entire path. Though the graph is still populated with other paths, the empty path was potentially evaluated during a later step which caused the issue.

\section{UPDATES}

\subsection{MARLIN SYNTAX ADDED}

Marlin is the syntax used by most desktop 3D printers. It is a syntax designed for Arduino based controllers printing with filament. The Marlin syntax has now been added as well as many accompanying settings needed to give the user control needed for the writer. This includes the filament settings such as extrusion multipliers and temperature control for the bed and extruders. With this addition, ORNL Slicer 2 can officially be used for desktop printers without post-processing of the G-Code.

\subsection{DYNAMIC ACCELERATION FOR MARLIN SYNTAX}

Dynamic acceleration is used for adjusting the gantry acceleration based on path type. Prior to this release, dynamic acceleration was only used for the Cincinnati syntax. With the addition of the Marlin syntax, new machines are available that can use dynamic acceleration via the M204 command. 


\subsection{FILE FOR G-CODE IMPORT}

CLI has been available within ORNL Slicer 2 as an export option, needed for prototype ORNL systems such as Saturn. CLI has now been added as an import option so that CLI files can be imported and visualized like other G-Code file types.

\subsection{UPDATED SLICER 2 ICON}

Prior to this update, the icon for Slicer 2 was the exact same as Slicer 1, the ORNL green oak leaf. The icon appears in the Title Bar, Menu Bar, and beside each settings category within the ORNL Slicer 2 Application. The icon is also used on the taskbar for Windows. This caused confusion when both ORNL Slicer and ORNL Slicer 2 were being run simultaneously, the identical icons could appear side by side on the task bar. A new icon has been created, Figure 5, and is visible throughout ORNL Slicer 2.

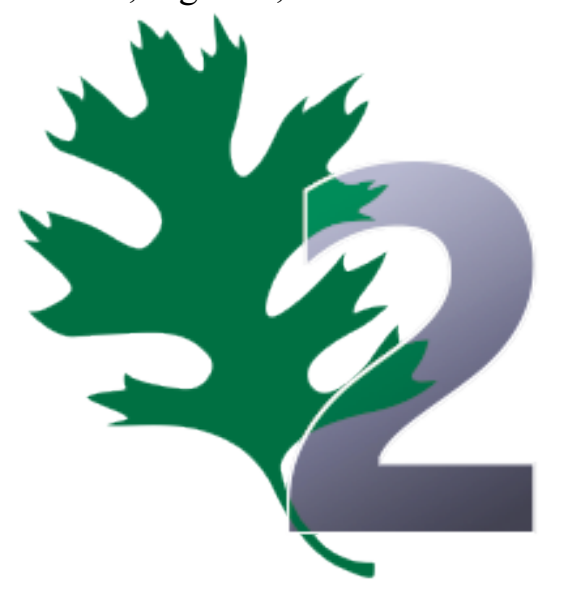

Figure 5: Updated ORNL Slicer 2 Icon

\section{NEXT VERSION}

The next version, ORNL Slicer 2 v0.94 BETA, is schedule for release on or about 4/27/21. 